\title{
Effect of Short-term Fluoride Release from Various Restorative Cements on Enamel Demineralization: An in vitro Study
}

\author{
${ }^{1}$ Shruti Patil, ${ }^{2}$ Mallikarjun Goud, ${ }^{2}$ Girija Sajjan \\ ${ }^{1}$ Reader, Department of Conservative Dentistry and Endodontics, SDM Dental College, Dharwad, Karnataka, India \\ ${ }^{2}$ Professor, Department of Conservative Dentistry and Endodontics, Bapuji Dental College, Davangere, Karnataka, India
}

Correspondence: Shruti Patil, Reader, Department of Conservative Dentistry and Endodontics, SDM Dental College, Dharwad Karnataka, India, e-mail: drshrutikulkarni@gmail.com

\section{ABSTRACT}

Purpose: Fluorides are probably the most commonly used anticaries agents. Due to this property they are incorporated into various restorative materials. The rate and amount of fluoride release, however, vary for different materials, which in turn determines the effectiveness of the restorative material in preventing demineralization around the restoration. To evaluate the fluoride release and area of demineralization of resin modified glass ionomers and compomers, and compare them with conventional glass ionomer cement and also to evaluate the relationship between the fluoride release and demineralization.

Materials and methods: A total of 32 human incisors were chosen and sectioned horizontally at CEJ, and the middle $2 \mathrm{~mm}$ of facial enamel isolated and restored with the test materials: Conventional glass ionomer cement (GIC), resin modified glass ionomer cement (RMGIC), compomer and resin composite. The specimens were observed under polarized light microscope with image analyzer to measure the area and depth of demineralization.

For fluoride release study, disks of test materials were suspended in deionized water and fluoride release was measured till a period of 4 days. Results: The area and depth of demineralization were least around the GIC, followed by RMGIC, compomer and composite $(p<0.05)$. A negative correlation was found between fluoride release and demineralization which was, however, not statistically significant.

Conclusion: The 4-day fluoride release was also higher for GIC as compared to RMGIC and Compomer.

Keywords: Fluoride, Demineralization, Glass ionomer cements, Resin modified glass ionomer cements, Compomer.

\section{INTRODUCTION}

The usefulness of fluoride releasing restorative materials for the prevention of enamel demineralization has been demonstrated by various model systems. ${ }^{1}$ Restorative materials that release fluoride have been noted to effectively inhibit demineralization of tooth structure adjacent to restorative margins. ${ }^{2,3}$

Conventional glass ionomers release high amounts of fluorides but do not perform as a good restorative material because of their high solubility, poor retention inadequate physical and esthetic properties. ${ }^{4}$ These materials are, hence, being slowly replaced by the more easily placed and esthetically better resin modified glass ionomers.

Conventional composites have a lot of advantages, like their ability to micromechanically bond to tooth structure, superior esthetic property and better physical properties. ${ }^{5}$ The obvious disadvantage of this material is its inability to release fluoride. Thus, a successor for composite was developed which was termed as “compomer” also known as "polyacid modified resin composites." 6,7

Although studies indicate the benefits of fluoride release from restorative materials, only a few of them provide information regarding relative levels of fluoride release. ${ }^{1}$ The differences in the effectiveness of materials in reducing enamel demineralization has been related to their relative levels of fluoride release. So, the current study was carried out to evaluate the short-term fluoride release characteristics of conventional glass ionomer cement (GIC), a resin modified glass ionomer cement (RMGIC) and a compomer and their ability to reduce enamel demineralization compared to a nonfluoride releasing control material and, to examine the relationship between the level of fluoride release and enamel demineralization.

\section{MATERIALS AND METHODS}

The study was carried out at the Department of Conservative Dentistry, Bapuji Dental College and Hospital, Davangere, Karnataka, India, in collaboration with Department of Chemical Engineering, Bapuji Institute of Engineering and Technology, Davangere, Karnataka, India.

The study involved two parts:

- Part I : To measure the areas of demineralization and lesion depth adjacent to the restorative material

- Part II: To evaluate the fluoride release from the restorative materials. 


\section{Part I: Measurement of Area and Depth of Demineralization}

A total of 32 human incisors free of fracture, caries, calculus stored in saline were chosen for the study (Fig. 1) and were randomly divided into four groups having eight teeth in each group. The teeth were sectioned horizontally at the CEJ using a diamond saw so that the crowns of the teeth could be obtained for the study. The middle $2 \mathrm{~mm}$ of the facial enamel of each tooth was isolated for the purpose of attaching a restorative material used in the study. Standard bonding procedures were used for each of the test materials. The following test materials were used in the study which were grouped as follows:

Group I : A conventional glass ionomer (restorative)—Fuji II (GC)

Group II : A resin modified glass ionomer-Vitremer (3M)

Group III : A compomer-Dyract (Dentsply De Tery)

Group IV : A hybrid resin-based composite-Z100 (3M)

After bonding, the specimen were kept in a humidifier for about 2 hours at 100\% humidity. Transparent nail varnish was applied at a distance of $1 \mathrm{~mm}$ from the test materials and also was applied onto the top surface of restored materials leaving the edges exposed. Each of these specimens were then suspended in $500 \mathrm{ml}$ of unstirred acidic buffer solution which consisted of $50 \mathrm{mM}$ acetic acid, $1.5 \mathrm{~mm}$ calcium nitrate tetrahydrate and $0.9 \mathrm{mM}$ potassium dihydrogen orthophosphate buffered to $\mathrm{pH}$ of 4.7 by $0.1 \mathrm{M}$ sodium hydroxide. ${ }^{1}$ The specimen were kept for 4 days to induce artificial lesion formation. All the specimen were thoroughly rinsed in distilled water upon removal from the acidic solution and were mounted in blocks of self cure acrylic and subjected to sectioning using a hard tissue microtome. From each specimen, a 150 um thick section was taken by sectioning parallel to the longitudinal axis of the tooth. The sections were fixed on to the slides and observed under polarized light microscope, projected at a magnification of 200×. Areas and depth of demineralization adjacent to the test material were measured using a grid system which had calibrations of 100, 200, 400, 600 and $800 \mathrm{~m}$ utilizing image analyzer software attached to the microscope.

\section{Part II: Evaluation of Fluoride Release}

Fluoride release from test materials was measured for 4 days. Disks ( $8.6 \mathrm{~mm}$ diameter and $1.65 \mathrm{~mm}$ depth) of the test materials were made by inserting the materials in the Teflon mold following manufacturers' instructions. Eight disks were made for each group of test materials. During the setting, dental floss was incorporated into the test materials. A glass plate was used to cover the open end of the mold during curing procedures. The disks were then polished using Super-Snap polishing disks (3M). The disks were then individually suspended in polyethylene containers with $25 \mathrm{ml}$ of deionized water and stored at $37^{\circ} \mathrm{C}$ until the time of each measurement. To measure the fluoride concentration in water, $10 \mathrm{ml}$ aliquot was removed and added to $10 \mathrm{ml}$ of total ionic strength adjusting buffer
(TISAB). An Orion fluoride electrode (Thermo Scientific, USA) with Orion ion analyzer was used to measure the concentration of eluted fluoride in the solution (in ppm). The disks were returned to their respective containers with fresh deionized water and stored at $37^{\circ} \mathrm{C}$ till the next measurement. The fluoride release by the materials was measured at the end of 24 hours and on the 2nd and 4th day.

\section{RESULTS}

In the present study, four different restorative materials, GIC (Fuji type II), RMGIC (Vitremer), compomer (Dyract) and composite resin (Z-100) were evaluated for area and depth of demineralization zone around the respective restorations when exposed to a demineralizing solution. The materials were also evaluated for the short-term (4th day) fluoride release and corelate it to enamel demineralization.

The mean area and the depth of demineralization were $750.73 \pm 174.18 \mu \mathrm{m}^{2}$ and $188.88 \pm 44.02 \mu \mathrm{m}$ for the GIC as compared to $1258.08 \pm 124.56 \mu^{2}$ and $241.63 \pm 32.91 \mu \mathrm{m}$ for RMGIC, $1683.84 \pm 93.12 \mu \mathrm{m}^{2}$ and $348.38 \pm 28.89 \mu \mathrm{m}$ for compomer and $2075.06 \pm 152.62 \mu \mathrm{m}^{2}$ and $398.63 \pm 35.56 \mu \mathrm{m}$ for composite (Table 1$)$. A statistically significant difference $(p<0.05)$ was found between the four materials when compared for the area and depth of demineralization (Table 2). The pairwise comparison revealed that the GIC had a significantly less area of demineralization and lesion depth, as compared to RMGIC, compomer and composite. The RMGIC had significantly lower area and depth of demineralization as compared to compomer and composite. The composite resin had significantly higher area and depth of demineralization as compared to the other three materials (Table 3).

The amount of fluoride release by the test materials is shown in Table 4. The GIC released the highest amount of fluoride till day 4 as compared to the other two materials. The fluoride release by composite resin was not evaluated. The area of demineralization was positively corelated to the depth of demineralization and was statistically significant. Even though the area and the depth of demineralization were negatively corelated to the amount of fluoride release, no statistical significance was noted (Table 5).

\section{DISCUSSION}

Enamel demineralization is the earliest step in caries formation and prevention or reduction, and enamel demineralization is the key to long-term caries control. Fluorides have been incorporated into restorative materials for their unique property of formation of fluorapatite crystals and thus making the enamel more resistant to acid breakdown and deminerailization. ${ }^{1}$ However, the amount and form of fluoride varies in different materials and this in turn determines how much fluoride gets released. A sustained fluoride release and an intimate contact of the restoration to the tooth margin are needed to facilitate the exchange of fluoride into the hydroxyapatite of the surrounding enamel. ${ }^{3,8}$ 
Effect of Short-term Fluoride Release from Various Restorative Cements on Enamel Demineralization: An in vitro Study

\begin{tabular}{|c|c|c|c|c|c|c|c|c|}
\hline \multirow[t]{2}{*}{ S.No. } & \multicolumn{2}{|c|}{ GIC } & \multicolumn{2}{|c|}{ RMGIC } & \multicolumn{2}{|c|}{ Compomer } & \multicolumn{2}{|c|}{ Composite } \\
\hline & Area $\left(\mu m^{2}\right)$ & $\begin{array}{c}\text { Lesion depth } \\
(\mu \mathrm{m})\end{array}$ & Area $\left(\mu m^{2}\right)$ & $\begin{array}{c}\text { Lesion depth } \\
(\mu \mathrm{m})\end{array}$ & Area $\left(\mu m^{2}\right)$ & $\begin{array}{c}\text { Lesion depth } \\
(\mu \mathrm{m})\end{array}$ & Area $\left(\mu m^{2}\right)$ & $\begin{array}{l}\text { Lesion depth } \\
\quad(\mu \mathrm{m})\end{array}$ \\
\hline 1 & 638.80 & 154.00 & 1201.30 & 224.00 & 1793.30 & 353.00 & 1935.70 & 411.00 \\
\hline 2 & 922.90 & 230.00 & 1479.30 & 279.00 & 1632.20 & 324.00 & 1919.30 & 424.00 \\
\hline 3 & 697.50 & 170.00 & 1372.10 & 260.00 & 1535.30 & 315.00 & 2012.20 & 379.00 \\
\hline 4 & 411.20 & 101.00 & 1133.30 & 204.00 & 1575.90 & 313.00 & 2179.50 & 360.00 \\
\hline 5 & 797.10 & 212.00 & 1129.20 & 224.00 & 1725.30 & 352.00 & 2259.40 & 352.00 \\
\hline 6 & 725.80 & 214.00 & 1321.20 & 296.00 & 1811.10 & 389.00 & 1979.70 & 382.00 \\
\hline 7 & 884.30 & 210.00 & 1255.40 & 232.00 & 1662.40 & 381.00 & 2002.60 & 430.00 \\
\hline 8 & 928.20 & 220.00 & 1172.80 & 214.00 & 1735.20 & 360.00 & 2312.10 & 451.00 \\
\hline Mean & 750.73 & 188.88 & 1258.08 & 241.63 & 1683.84 & 348.38 & 2075.06 & 398.63 \\
\hline Std. dev & 174.19 & 41.18 & 124.56 & 32.91 & 99.55 & 28.89 & 152.62 & 35.56 \\
\hline
\end{tabular}

Statistically significance at $\mathrm{p}<0.05$

Table 2: Comparision between the groups for area of demineralization and lesion depth

\begin{tabular}{llcccc}
\multicolumn{5}{c}{ Table 2: Comparision between the groups for area of demineralization and lesion depth } \\
\hline Data & Groups & Means & Std. deviation & F-value & p-value \\
\hline \multirow{2}{*}{ Area of demineralization $\left(\mu \mathrm{m}^{2}\right)$} & GIC & 750.73 & 174.19 & 130.99 & 0.00 \\
& RMGIC & 1258.08 & 124.56 & & \\
& Compomer & 1683.84 & 99.55 & & \\
& Composite & 2075.06 & 152.62 & \\
Lesion depth $(\mu \mathrm{m})$ & GIC & 188.88 & 44.02 & 32.91 & \\
& RMGIC & 241.63 & 28.89 & \\
& Compomer & 348.38 & 35.56 & & \\
\hline
\end{tabular}

Statistically significance at $\mathrm{p}<0.05$

\begin{tabular}{llllll}
\multicolumn{5}{c}{ Table 3: Pairwise comparison by Newman-Keuls multiple posthoc tests } \\
\hline Data & Groups & GIC & RMGIC & Compomer & Composite \\
\hline Area of demineralization $\left(\mu \mathrm{m}^{2}\right)$ & Mean & 750.72 & 1258.10 & 1683.80 & 2075.10 \\
& GIC & - & - & - & - \\
& RMGIC & 0.00 & - & - & - \\
& Compomer & 0.00 & 0.00 & - & - \\
Lesion depth $(\mu \mathrm{m})$ & Composite & 0.00 & 0.00 & 348.38 & 398.63 \\
& Mean & 188.88 & 241.63 & - & - \\
& GIC & - & - & - & - \\
& Group II & 0.00 & - & - & - \\
& Group III & 0.00 & 0.00 & 0.01 & - \\
\hline
\end{tabular}

Statistically significance at $\mathrm{p}<0.05$

The glass ionomer and composite resin are two of the most commonly used restorative materials. Both have their own advantages and disadvantages, regarding esthetics and anticariogenic activity. To overcome these disadvantages, resin modified GIC and compomers were devised which have an inherent property of fluoride release.

In the present study, the area and depth of demineralization of teeth sections restored with the test materials when exposed to a demineralizing solution, and the amount of fluoride release by the test materials over a short period of time (4 days) was carried out.
Among the three groups of fluoride releasing restorative materials, GIC showed a least area of enamel demineralization and lesion depth and highest amount of fluoride release followed by RMGIC and then followed by compomer. When the fluoride release profile was carried out for all the three materials, it was observed that the highest amount of fluoride was eluted in the first 24 hours and the levels dropped over time. ${ }^{9,10}$

Conventional GIC releases significant amounts of fluoride. This material is classified as "a water-based material that harden following an acid-base reaction between flour alumino silicate 


\begin{tabular}{|c|c|c|c|c|c|c|c|c|c|c|c|}
\hline Group & Days & 1.00 & 2.00 & 3.00 & 4.00 & 5.00 & 6.00 & 7.00 & 8.00 & Mean & Std. dev \\
\hline \multirow[t]{4}{*}{ GIC } & 24.00 & 30.91 & 32.48 & 30.39 & 31.84 & 30.11 & 28.98 & 29.04 & 30.88 & 24.20 & 3.54 \\
\hline & $2 \mathrm{~d}$ & 19.99 & 19.71 & 19.91 & 19.89 & 18.99 & 18.56 & 18.44 & 19.82 & 18.92 & 0.60 \\
\hline & $4 \mathrm{~d}$ & 13.68 & 13.71 & 13.33 & 13.80 & 13.11 & 13.94 & 13.60 & 13.40 & 13.07 & 0.51 \\
\hline & Cum. fluoride release till day 4 & 64.58 & 65.90 & 63.63 & 65.53 & 62.21 & 61.48 & 61.08 & 64.10 & 63.56 & 1.70 \\
\hline \multirow[t]{4}{*}{ RMGIC } & 24.00 & 30.91 & 32.48 & 30.39 & 31.84 & 30.11 & 28.98 & 29.04 & 30.88 & 24.20 & 0.42 \\
\hline & $2 \mathrm{~d}$ & 19.99 & 19.71 & 19.91 & 19.89 & 18.99 & 18.56 & 18.44 & 19.82 & 18.92 & 0.22 \\
\hline & $4 \mathrm{~d}$ & 13.68 & 13.71 & 13.33 & 13.80 & 13.11 & 13.94 & 13.60 & 13.40 & 13.07 & 0.58 \\
\hline & Cum. fluoride release till day 4 & 43.96 & 44.11 & 42.16 & 43.93 & 44.72 & 43.50 & 43.45 & 44.16 & 43.75 & 0.71 \\
\hline \multirow[t]{4}{*}{ Compomer } & 24.00 & 30.91 & 32.48 & 30.39 & 31.84 & 30.11 & 28.98 & 29.04 & 30.88 & 24.20 & 0.42 \\
\hline & $2 \mathrm{~d}$ & 19.99 & 19.71 & 19.91 & 19.89 & 18.99 & 18.56 & 18.44 & 19.82 & 18.92 & 0.22 \\
\hline & $4 \mathrm{~d}$ & 13.68 & 13.71 & 13.33 & 13.80 & 13.11 & 13.94 & 13.60 & 13.40 & 13.07 & 0.58 \\
\hline & Cum. fluoride release till day 4 & 25.73 & 25.31 & 25.99 & 25.87 & 24.66 & 24.31 & 26.11 & 25.52 & 25.44 & 0.61 \\
\hline
\end{tabular}

Statistically significance at $\mathrm{p}<0.05$

Table 5: Correlation between demineralization and lesion depth and fluoride release on day 4: Group I, Group II and Group III

\begin{tabular}{|c|c|c|c|c|}
\hline & Variable & Demineralization & Lesion depth & Fluoride release \\
\hline \multirow[t]{3}{*}{ GIC } & Demineralization & 1.00 & - & - \\
\hline & Lesion depth & 0.94 & 1.00 & - \\
\hline & Fluoride release & -0.28 & -0.41 & 1.00 \\
\hline \multirow[t]{3}{*}{ RMGIC } & Demineralization & 1.00 & & - \\
\hline & Lesion depth & 0.84 & 1.00 & - \\
\hline & Fluoride release & -0.47 & -0.37 & 1.00 \\
\hline \multirow[t]{3}{*}{ Compomer } & Demineralization & 1.00 & - & - \\
\hline & Lesion depth & 0.78 & 1.00 & - \\
\hline & Fluoride release & -0.61 & -0.42 & 1.00 \\
\hline
\end{tabular}

Statistically significance at $\mathrm{p}<0.05$

glass powder and an aqueous solution of poly acid. ${ }^{11}$ The increased level of fluoride is due to erosive leaching of glass particles in the bulk of cement and diffusion of the leached fluoride through the porous cement matrix. This fluoride gets incorporated within the adjacent tooth structure, forming flour apatite or hydroxyl flour apatite. ${ }^{10}$

The lesser fluoride release from the RMGIC and can be attributed to its setting reaction. The setting reaction of RMGIC as "dual setting”, in which both polymerization and acid base reaction take place. ${ }^{11,12}$ The latter takes place by the virtue of HEMA, which is a hydrophilic monomer, which absorbs water and results in the reaction. The greater area of demineralization in this group is caused by lesser fluoride release as compared to GIC. The mechanism by which fluoride acts on adjacent tooth surface is similar to that of GIC. 3,12,13

The lower release of fluoride from Compomer can be explained by the fact that these products are hydrophobic resins which set by polymerization. ${ }^{5}$ These do not contain water, as seen in conventional and resin modified glass ionomers, but they absorb water after weeks of curing thereby resulting in an acid-base reaction, which is secondary thus the amount of fluoride released by this group is lesser.
The conventional composite resin material that does not contain fluoride was used as a control material.

The areas and the depth of demineralization were compared with the cumulative 4th day fluoride release to examine dose response relationship. A negative correlation was found for fluoride releasing agents, which indicated that as the amount of fluoride release increased, the area and depth of demineralization reduced and vice versa. The results of this study indicate that fluoride released from materials can exert an inhibiting effect on demineralization of enamel adjacent to the material. ${ }^{1}$ The range and degree of protection is directly related to the level of fluoride release.

As the amount of fluoride eluted has a direct effect on inhibition of secondary caries, it can be thought that higher the fluoride release, better the material. But, when selecting a material for clinical use, however, it must be remembered that fluoride release is one of the multiple factors to be considered.

The current study shows that conventional glass ionomer cement (Fuji II) releases the highest amount of fluoride and has the least amount of demineralization followed by RMGIC (Vitremer) and later followed by compomer (Dyract), and the highest amount of fluoride eluted is at the end of 24 hours after 
which consistently lower amount of fluoride elution is observed, which occurs over long periods.

\section{REFERENCES}

1. Glasspoole EA, Erickson RL, Davidson CL. Demineralization of enamel in relation to the fluoride release of materials. Am J Dent 2001;14:8-12.

2. Donly KJ, Segura A. Fluoride release and caries inhibition associated with a resin-modified glass ionomer cement at varying fluoride loading doses. Am J Dent 2002;15:8-10.

3. Tam LE, Chan GPL, Yim D. In vitro caries inhibition effects by conventional and resin-modified glass ionomer restorations. Operative Dentistry 1997;22:4-14.

4. Hicks JM, Flaitz CM. Resin-modified glass ionomer restorations and in vitro secondary caries formation in coronal enamel. Quintessence Int 2000;31:570-78.

5. Albers HF. Resin ionomers. In tooth coloured restorativesPrinciples and techniques (9th ed). BC Decker Inc 2002; 57-67.

6. Eliades G, Kakaboura A, Palaghias G. Acid base reaction and fluoride release profiles in visible light cured polyacid- modified composite restoratives (compomers). Dent Mater 1998;14:57-63.

7. Yip RK, Smales RJ. Fluoride release from a polyacid-modified resin composite and 3 resin-modified glass ionomer materials. Quintessence Int 2000;31:261-66.

8. Freedman R, Diefenderfer KE. Effects of daily fluoride exposures on fluoride release by glass ionomer-based restoratives. Operative Dentistry 2003;28(2):178-85.

9. Mallakh El BF, Sarkar NK. Fluoride release from glass ionomer cements in deionized water and artificial saliva. Dent Mater 1990;6:118-22.

10. Creanor SL, et al. Fluoride uptake and release characteristics of glass ionomer cements. Caries Res 1994;28:322-28.

11. Kakaboura A, Eliades G, Palaghias G. An FTIR study on the setting mechanism of resin-modified glass ionomer restoratives. Dent Mater May 1996;12(3):173-78.

12. Momoi Y, McCabe JF. Fluoride release from light activated glass ionomer restorative cements. Dent Mater 1993;9:151-54.

13. Eliades G. Chemical and biological properties of glass ionomer cements in advances in glass ionomer cements. Davidson CL, Mjor IA (Eds). Quintessence Publishing. IL 1999;85-101. 